\title{
Modelling The Human Values Scale from consumers transactional Data Bases
}

\author{
Javier Guzmán-Obando, Gustavo González, Josep L. de la Rosa, Ronald U. Ruiz \\ Institute of Informatics and Applications \\ University of Girona, Spain \\ \{jguzmano,gustavog,peplluis,ruruizo\}@eia.udg.es
}

José A. Castán

Faculty of Engineering "Arturo Narro Siller"

Autonomous University of Tamaulipas, Mexico

jacastan@uat.edu.mx

\begin{abstract}
The main objective of this paper aims at developing a methodology that takes into account the human factor extracted from the data base used by the recommender systems, and which allow to resolve the specific problems of prediction and recommendation. In this work, we propose to extract the user's Human Values Scale from the data base of the users, to improve their suitability in open environments, such as the recommender systems. For this purpose, the methodology is applied with the data of the user after interacting with the system. The methodology is exemplified with a case study.
\end{abstract}

\section{Introduction}

Personalization of services using a user's Human Values Scale (HVS) can improve his/her satisfaction. According to [6], the information society will be followed by a society in which individuals will prioritize their decisions in interactions that involve a high degree of emotion, which will be a relevant issue in their values scale. Therefore, we are witnessing a cyclical transformation in society affecting its values scale.

In traditional psychology [11] the HVS is treated as the set of desirable and non-situational goals whose significance can vary from one person to another and govern their life like a set of individual principles.

Recommender systems (RS) represent user preferences for the purpose of suggesting items to purchase or examine. They have become fundamental applications in electronic commerce and information access, providing suggestions that effectively prune large information spaces so that users are directed toward those items that best meet their needs and preferences [1].

The important point in this research is to obtain the HVS from the user profile which is obtained from the data base (DB). The users profile corresponds to the modelling of an object in a compact way with its main characteristics [5]. This profile includes not only personal data and computing system characteristics but also behaviour guidelines, personal interests and preferences. It is represented by a structure of data suitable for its analysis, recovery and use. In computing terms, an user profile is the representation of a set of characteristics that describe a person in the role of user of a given adaptative system.

An user profile is usually registered in a attributevalue way. The system keeps, analyse and release this information to the adaptable part. The aspects to take into account for the developing of the users profiles are: which is the relevant information, how to obtain it, how to represent it, how to keep it up-dated, which recovery methods to implement and how to use the information to adapt the system in an authomatic way.

The important point in this research is to obtain the HVS from the consumer profile which is obtained from the DB. The consumers profile corresponds to the modelling of an object in a compact way with its main characteristics [5].

Our research is focused on the analysis of HVS using the Schwartz Value Survey (SVS) [11], which can take advantage of the DB through its attributes to define a methodology that responds with more exactitude to preferences and interests of the consumer. 
The paper is organized as follows. In Section 2, a brief introduction to work related to the HVS is presented. Section 3 gives a study of the HVS in DB for RS. In Section 4, we describe the methodology proposed to obtain the HVS of the consumer from DB. Next, in Section 5, we illustrate the proposed methodology through a RS of banking services. Finally, Section 6 offers some conclusions and suggestions for future work.

\section{Related work}

Research studies [9] have proved the influence of human values on the perception and decision making of human beings. These studies reveal the value structure of each individual, in particular the values to which a greater or smaller importance is assigned, as they play a determining a role in perception as in decision making. We carried out an analysis of the most used scales on research for measuring human values [7]. Some do not measure the range of human values relevant in many life domains; others, despite their intention of covering the range of human values comprehensively, leave out critical content (e.g., tradition and power values); in other cases some items are highly sensitive to prevailing economic conditions and measure individuals' values only indirectly. We consider that the most suitable technique to apply in this research is the Schwartz scale of values, as it covers 56 human values included in 10 basic values (see Table 1). The reliability and validity of the Schwartz value survey have been demonstrated in several studies [6] and [11]. The Schwartz Value Survey [10] consists of 40 items, each one associated with an asymmetric scale from one (opposed to personal values) to six (of supreme importance), indicating the importance of this value as a guiding principle in the user's life. The survey items are distributed among 10 universal dimensions (see Table 1 and Figure 2.a), which respond to different underlying motivations of the values integrating them. We call these dimensions meta-attributes. They are grouped taking into account compatible typologies and the diametrically opposed incompatible typologies (see Figure 1), which represent a contradiction of objectives that would generate a conflict in the user.

\begin{tabular}{cc} 
Table 1: Types of value postulated by Schwartz \\
\hline $\begin{array}{c}\text { Type of } \\
\text { Value }\end{array}$ & Motivation to which it responds \\
\hline Power & $\begin{array}{l}\text { Attainment of social status and prestige, } \\
\text { and the control or dominance over people } \\
\text { and resources. }\end{array}$
\end{tabular}

\begin{tabular}{|c|c|}
\hline $\begin{array}{l}\text { Type of } \\
\text { Value }\end{array}$ & Motivation to which it responds \\
\hline Achievement & $\begin{array}{l}\text { Personal success through demonstrated } \\
\text { competence. Competence is evaluated in } \\
\text { terms of what is valued by the system or } \\
\text { organization in which the individual is } \\
\text { located. }\end{array}$ \\
\hline Hedonism & $\begin{array}{l}\text { Pleasure or sensuous gratification for } \\
\text { oneself. This value type is derived from } \\
\text { physical needs and the pleasure } \\
\text { associated with satisfying them. }\end{array}$ \\
\hline Stimulation & $\begin{array}{l}\text { Excitement, novelty and challenge in life. } \\
\text { This value type is derived from the need } \\
\text { for variety and stimulation in order to } \\
\text { maintain an optimal level of activation. }\end{array}$ \\
\hline $\begin{array}{l}\text { Self- } \\
\text { Direction }\end{array}$ & $\begin{array}{l}\text { Independent thought and action (for } \\
\text { example, choosing, creating, exploring). } \\
\text { Self-direction comes from the need for } \\
\text { control and mastery along with the need } \\
\text { for autonomy and independence. }\end{array}$ \\
\hline $\begin{array}{l}\text { Universalis } \\
\mathrm{m}\end{array}$ & $\begin{array}{l}\text { Understanding, appreciation, tolerance, } \\
\text { and protection of the welfare for all } \\
\text { people and for nature. }\end{array}$ \\
\hline Benevolence & $\begin{array}{l}\text { Preserve and enhance the welfare of } \\
\text { people with whom one is in frequent } \\
\text { personal contact. This is a concern for } \\
\text { the welfare of others that is more } \\
\text { narrowly defined than Universalism. }\end{array}$ \\
\hline Tradition & $\begin{array}{l}\text { Respect, commitment, and acceptance of } \\
\text { the customs and ideas that one's culture } \\
\text { or religion imposes on the individual. A } \\
\text { traditional mode of behaviour becomes a } \\
\text { symbol of the group's solidarity and an } \\
\text { expression of its unique worth and, } \\
\text { hopefully, its survival. }\end{array}$ \\
\hline Conformity & $\begin{array}{l}\text { Restraint of action, inclinations, and } \\
\text { impulses likely to upset or harm others } \\
\text { and violate social expectations or norms. } \\
\text { It is derived from the requirement that } \\
\text { individuals inhibit inclinations that might } \\
\text { be socially disruptive in order for } \\
\text { personal interaction and group } \\
\text { functioning to run smoothly. }\end{array}$ \\
\hline Security & $\begin{array}{l}\text { Safety, harmony, and stability of society } \\
\text { or relationships, and of self. }\end{array}$ \\
\hline
\end{tabular}

\section{The HVS in DB for RS}

The DB concept fixes some of its own characteristics, for example: The real world considers inter-relations between data and semantic restrictions which must be present in a DB. In a DB are kept not only entities and attributes but also inter-relations between data. On the other hand, nowadays a great importance is given to the semantic restrictions, so these are kept together with the data. These characteristics are important to create the consumers 
HVS from the DB. In our research, the general information of the consumer is useful for the recommendation process since we can deduce that the values scale can be applied to flexible entities, for instance a DB.

Values act as a central means of rationalizing action within the human mind. Given a goal, values dictate the way in which the goal will be accomplished [2]. The values scale is represented by goals (implicit or explicit) which are conscious of the needs of every flexible and autonomous social entity.

The HVS is an integral approach to consumer and can take advantage of the DB using its characteristics in order to use them in the processes of the recommendation [8].

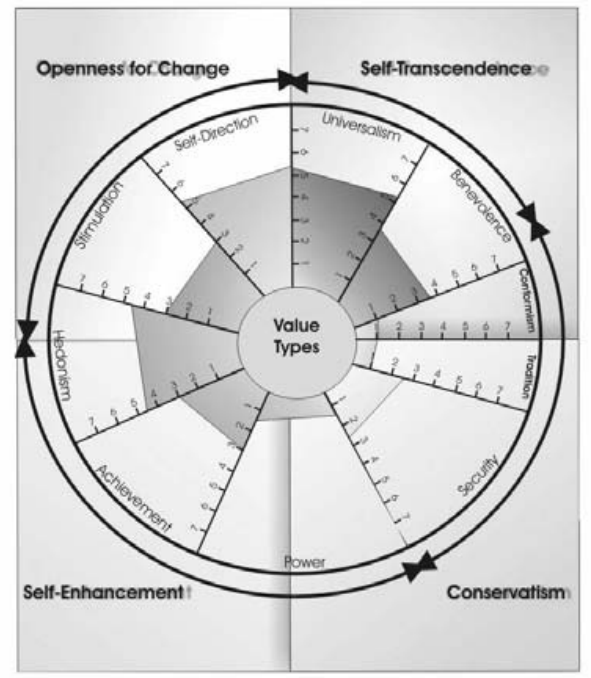

Figure 1. Dynamic structure of values according to the universal theory of Schwartz.

\section{Obtaining the HVS of a consumer from DB}

To calculate the HVS of a consumer, we must first obtain the consumer's general characteristics from the DB by applying the SVS. Then, through the proposed method, support will be given to the RS to make suggestions as a function of the his/her HVS.

\subsection{The HVS Test}

The SVS provides a set of universal values classified into four groups: Openness to Change, Conservatism, Self-transcendence, and Selfenhancement. These four groups are further divided into 10 sets of universal values (described above), which have $\mathrm{n}$ items to calculate the consumer HVS Each item is defined in $[0,1]$. (see Figure 2.a).

\subsection{Information distribution}

The values of the DBs from the RS provide relevant information about the consumer, from which we wish to obtain the HVS. In our model, the technique represents the values as points in a multidimensional space. Distances between points reflect empirical relations between the values that can be measured by the correlations between the scores that give their importance for the person. A bigger conceptual similarity between two values shows that they are more related empirically, and therefore they will be closer in the multidimensional space. Figure 1 shows the items related to the HVS.

According to Figure 1, the set of parameters that define the HVS are:

$$
\begin{array}{ll}
E v h=\left\{V u_{1}, \ldots, V u_{n}\right\} & \text { Vu=Universal values } \\
V u=\left\{V h_{1}, \ldots, V h_{n}\right\} & \text { Vh=human values } \\
V h=\left\{a_{1}, \ldots, a_{n}\right\} & \text { a }=\text { values or attributes }
\end{array}
$$

4.2.1. Recommendation. The objective of this stage is to take advantage of the consumer HVS to provide information to the RS to improve the recommendations made to the consumer. To achieve this objective, the following methodology will be used.

4.2.2. Calculation of numerical values. In this stage, the calculations are made to obtain the consumer HVS, following a series of steps.

Step 1: Obtain the individual qualification of each $V h$ :

$$
V a l_{-} \operatorname{Num}(V h)=\frac{\sum_{i=1}^{i=n_{a}} V a l_{-} \operatorname{Num}\left(a_{i}\right)}{n_{a}} \in[0,1]
$$

Where: $n_{a}=$ number of attributes evaluated in $V h$.

Step 2: Calculate the numerical value of each $V u$ :

$$
V a l_{-} \operatorname{Num}(V u)=\frac{\sum_{i=1}^{i=n h h} V a l_{-} \operatorname{Num}\left(V h_{i}\right)}{n_{V h}} \in[0,1]
$$

Where: $n_{a}=$ number of attributes evaluated in $V u$.

Step 3: Perform the global calculation of the consumer HVS:

$$
E v h=\frac{\sum_{j=1}^{j=n v u} V a l_{-} \operatorname{Num}\left(V u_{j}\right)}{n_{V u}} \in[0,1]
$$

Where: $n_{V u}=$ total number of universal values in the HVS. 
4.2.3. Generating recommendations. Although the effectiveness of existing recommender systems is remarkable, they still have serious limitations as they are unable to perform qualitative inference on the recommendations they offer and are incapable of dealing with the defeasible nature of users' preferences. In this context, defeasible argumentation frameworks [4] have evolved to become a sound setting to formalize common sense qualitative reasoning.

In the last years several specialized techniques for improving web search have been developed. Most existing approaches are still limited, mainly due to the absence of qualitative criteria for ranking results and insensitivity to user preferences for guiding the search. At the same time, defeasible argumentation evolved as a successful approach in AI to model common sense qualitative reasoning with applications in many areas, such as agent theory, knowledge engineering and legal reasoning [3].

We contend that defeasible argumentation, propose methodology in [3], can be integrated into existing recommender system technologies, paving the way to solve the problems of the recommender processes.

We will analyze our proposal in the next section, illustrating it with a case study.

\section{Illustration}

We illustrate the proposed methodology through a RS for banking services. Nowadays, banks offer their customers products and services using RS, taking into account their interests, preferences and attitudes, and the consumer's interactions with the system (transactions). DB registers the consumer's movements so that the RS can offer more suitable solutions that will increase the confidence of the customer in the banking organization. This allows the bank to know the customer, interpreting his/her necessities, capacities and attitudes to consumption. Banking transactions that would help the recommendation process include card contracts, relationship indicators, movements of current account, domiciled invoices, card movements, and income. The case study develops thanks to the data provided by the company Agents Inspired Technology (AIT) on the transactions from the banking services of a bank we call Bank A; with more than 3 millions customers, the data corresponds to the movements accomplished during the period 9904. For this case study, we develops an example from one of the thousand operations practised by Bank A.

\subsection{Description}

Assume an intelligent agent $\mathrm{A}$ with a knowledge base $(K, \Delta)$ that contains information on the conditions under which Services Bank A, according to the HVS of their customers, offer a credit service to purchase a high technology hybrid vehicle. To offer credit for this type of product, the bank conditions are that the customer: 1) must have a high degree of openness to change; 2) must have a high score in the values group of self-enhancement; 3 ) because of the product/service offered, the level of conservatism must be less that $50 \%$; and 4) the level of self-transcendence must be less than $50 \%$.

The data kept in the bank DB, are used to obtain the HVS of the costumer from the transactions realised by the consumer, for example: If the DB has information on Jordi Vilá carrying out 7800 euros monthly deposits then the power value has a score of 0.75 . If Jordi Vilá spends regularly on leasure activities such as pubs, restaurants or clubs then the score for the pleasure value is 0.80 . And so on to obtain information from the DB and therefore the numerical score for all the values contained in the HVS (see Figure 2.b.).

\subsection{Applying the methodology}

Following the methodology proposed by [8], the general characteristics of the consumer are obtained through the DB that computes the consumer data for the bank's RS. According to (3), and as a result of applying the SVS, we obtain the following results.

$$
\begin{gathered}
V h=\left\{\begin{array}{c}
\text { val }(\text { broad } \min \mathrm{ded}, 0.60), \operatorname{val}(\text { Wisdom }, 0.40), \\
\text { val }(\text { social_justice }, 0.40), . .,(\text { an_exciting_life }, 0.80)
\end{array}\right\} \\
\text { We calculate the consumers HVS from the DB. }
\end{gathered}
$$

Step 1: Applying equation 4, we obtain the 10 human values of the consumer as follows.

$$
\begin{aligned}
& \begin{array}{l}
\operatorname{val}(\text { broad } \min d e d)+\operatorname{val}(\text { wisdom })+ \\
\operatorname{val}(\text { social_justice })+\operatorname{val}(\text { equality })+ \\
\operatorname{val}\left(a_{-} \text {world_at_peace }\right)+
\end{array} \\
\text { Val_Num(Universalism })= & \frac{v a l(\text { unity_with_natura })}{6} \\
= & \frac{2.40}{6}=0.40
\end{aligned}
$$

In the same way we calculate the other human values:

$$
\begin{aligned}
& \text { Val_Num }(\text { Benevolence })=0.51 \text {; } \\
& \text { Val_Num }(\text { Conformity })=0.65 \text {; } \\
& \text { Val_Num }(\text { Tradition })=0.12 ; \text { Val_Num }(\text { Security })=0.55 ; \\
& \text { Val_Num }(\text { Achievement })=0.84 \text {; }
\end{aligned}
$$


Val_Num $($ Power $)=0.70 ;$ Val_Num $($ Hedonism $)=0.73$;

Val_Num $($ Self_direction $)=0.87$;

Val_Num $($ Stimulation $)=0.67$

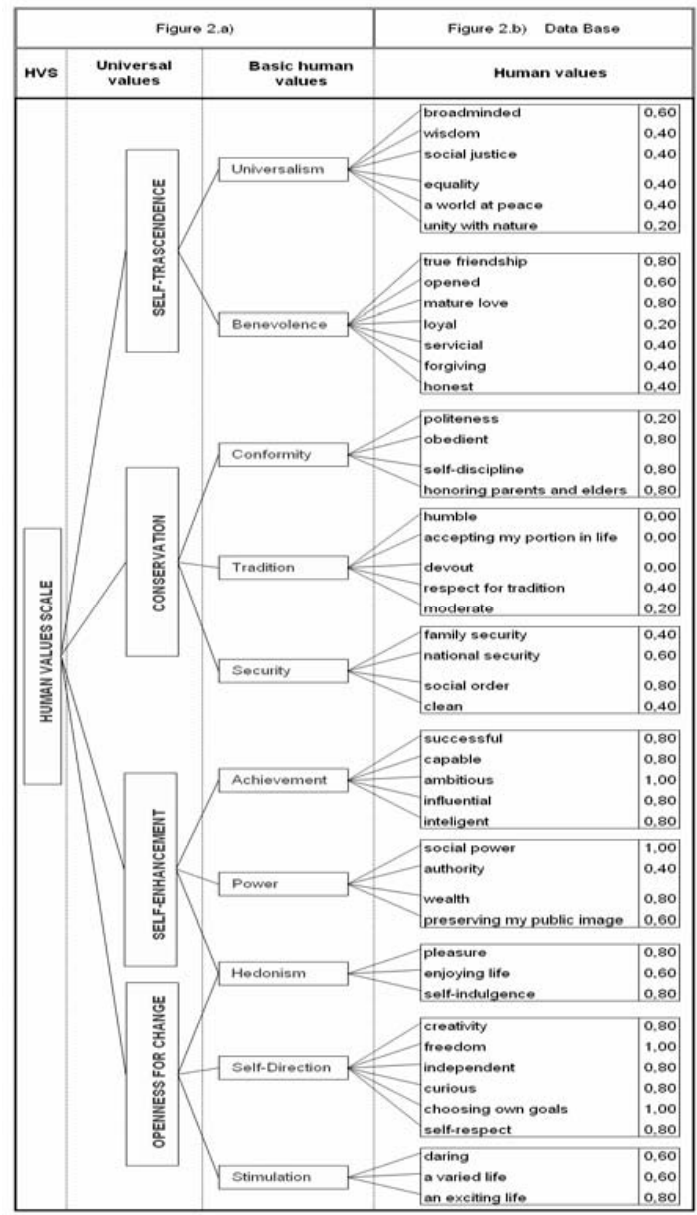

Figure 2. Parameters tree to classify the HVS.

Step 2: Using equation 5, we calculate the 4 groups which correspond to the universal values of the HVS

$$
\begin{aligned}
& \text { Val_Num }(\text { Self_trascendence })= \\
& \frac{\text { Val_Num }(\text { Universalism })+\text { Val_Num }(\text { Benevolence })}{2}=0.46
\end{aligned}
$$

Analogously we can compute the next 3 universal values.

$$
\begin{gathered}
\text { Val_Num }(\text { Conservatism })=0.44 \\
\text { Val_Num }(\text { Self_Enhancement })=0.76 \\
\text { Val_Num }(\text { Openness_to_change })=0.76
\end{gathered}
$$

Step 3: In this last step we calculate the consumer HVS using equation 6 .

$$
E v h=
$$

$($ Val_Num(Self_trascendence $)+$ Val _ Num(Conservatism $)$ + Val_Num(Self_enhancement $)+$ Val_Num(Openness_to_change))

$$
=(0.46+0.44+0.76+0.76) / 4=2.42 / 4=0.60
$$

Once obtained the HVS we can carry on with the recommendation process by using an approach with defeasible argumentation.

\subsection{Alternative with defeasible argumentation}

One solution to the problem is by using defeasible argumentation. Considering that the bank conditions for offering the credit service to Jordi Vilá affect the four main universal values groups directly, these will be considered in the recommender process.

5.3.1. First consumer case. If $(K, \Delta)$ is the knowledge base defined in 5.1 The group $\operatorname{PredName}(\mathrm{K}, \Delta)$ associated can be divided in the following way.

$\operatorname{Pr}$ edBase $(L)=\{$ conservatism, self_trascendence $\} ;$ and,

$\operatorname{Pr} e d \operatorname{Deriv}(L)=\left\{\begin{array}{l}\text { openness_to_change, self_enhancement }, \\ \text { oferr_service }\end{array}\right\}$

Therefore, the logic defeasible argumentation is as follows:

$$
\begin{gathered}
\Delta=\left\{\begin{array}{l}
\text { Openness_to_change }(x) \wedge \text { Self_enhancement }(x) \\
\succ \text { offer_service }(x, y), \\
\text { Openness_to_change }(x) \succ \neg \text { Conservatism }(x), \\
\text { Self_enhancement }(x) \succ \neg \text { Self_trascendence }(x)
\end{array}\right\} \\
\kappa_{G}=\left\{\begin{array}{l}
\text { Conservatism }(x) \rightarrow \neg \text { Openness_to_change }(x), \\
\text { Self_trascendence }(x) \rightarrow \neg \text { Self_enhancement }(x)
\end{array}\right\}
\end{gathered}
$$

Considering the universal values group from Jordi Vilá, we have:

The possible values to measure the grade or level of score from the universal values is given by:

$$
L_{n}: \text { nvalues }\{0,1 /(n-1), 2 /(n-1), \ldots,(n-2) /(n-1), 1\}
$$

Therefore:

$$
\begin{array}{cc}
A(x)=\text { very_high }_{-}\left(A_{I}(x)\right)=1 & A(x)=\operatorname{high}\left(A_{i}(x)\right)=A_{i}^{0.75}(x) \\
A(x)=\text { medium }\left(A_{i}(x)\right)=A_{i}^{0.50}(x) & A(x)=\operatorname{low}\left(A_{i}(x)\right)=A_{i}^{0.25}(x) \\
A(x)=\operatorname{verylow}\left(A_{i}(x)\right)=A_{i}^{0}(x)=0 &
\end{array}
$$

Then:

$$
\begin{gathered}
\text { Openness_to_change }(\text { Jordi_Vilá }))=0.76>0.75 \\
\text { Self_Enhancement }(\text { Jordi_Vilá })=0.76>0.75 \\
\text { Conservatism }(\text { Jordi_Vilá })=0.44<0.50
\end{gathered}
$$




$$
\text { Self_trascendence }\left(J o r d i \_V i l a ́\right)=0.46<0.50
$$

Note that in all four groups, conditions for the bank to offer the service to the consumer Jordi Vila are fulfilled. Therefore the system recommends sending the brochure and all the details regarding the credit service to this distinguished customer.

5.3.2. Second consumer case. Suppose that for the same problem, we have the HVS from the consumer Montse Rovira, which data are the following:

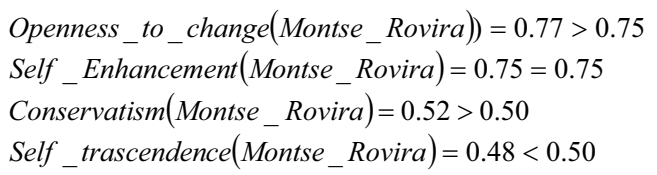

In this case, according to the logic defeasible argumentation, the argument:

$$
A_{1}=\left\{\operatorname{Self} \_ \text {trascendence }(x) \rightarrow \neg \text { Self_enhancement }(x)\right\}
$$

contra argument to:

$$
\begin{aligned}
& A_{1}=\{\text { Openness_to_change }(x) \wedge \text { Self_enhancement }(x) \\
& \succ \text { offer_service }(x, y)\}
\end{aligned}
$$

therefore the system recommend to the bank not to offer the credit service to the consumer Montse Rovira.

\section{Conclusions and future works}

In this paper, we show a methodology based on defeasible argumentation to RS based on the consumer's HVS. This HVS is obtained directly from the data base.

Through the proposed methodology, it is possible to calculate the HVS from the DB without disturbing the consumer with surveys. The preliminary results obtained from the illustration, in section 5, on banking services show that the HVS of the consumers is important to improve the recommender processes.

In future, we will work on the implementation of this methodology to test it using machine-learning techniques to obtain better recommendations in multiple areas. It is intended to extend the use of defeasible argumentation to obtain diverse techniques to improve the consumer's decision making.

\section{Acknowledgements}

This research has been supported through Autonomous University of Tamaulipas. To the DPI2005-09025-C02-02 grant of the Spanish gov. "Cognitive Control Systems".

\section{References}

[1] R. Burke, "Hybrid recommender systems: Survey and experiments", User Modeling and User-Adapted Interaction, 12(4), 2002

[2] J. Carter and A. Ghorbani A., "Value Centric Trust in Multiagent Systems, Faculty of Computer Science", University of New Brunswick Fredericton, NB, E3B 5A3, Canada, 2004.

[3] C. Chesñevar and A. Maguitman, "ARGUENET: An Argument-Based Recommender System for Solving Web Search Queries", IEEE Conference on Intelligent Systems, Varna, Bulgaria, 2004.

[4] C. Chesñevar, J. Dix, F. Stolzenburg, and G. Simari, "Relating Defeasible and Normal Logic Programming through Transformation Properties", Theoretical Computer Sc., 290(1), 2003

[5] R. da Cruz, García Peñalbo F. and Romero L. "Perfiles de usuario en la senda de la personalización", Technical report, Universidad de Salamanca - Departamento de Informática y Telemática, Enero 2003.

[6] V.V. Gouveia, M. Clemente, and M.A. Vidal, "El cuestionario de valores de Schwartz (CVS): propuesta de adaptación en el formato de respuesta", Revista de Psic. Social, (15)3, 1998.

[7] J. Guzmán, Research Work Report: "Methodology to obtain the user's Human Values Scale from Smart User Models", Department of Electronics, Computer Science and Automatic Control University of Girona, http://eia.udg.es/ / jguzmano/PublicacionesJGO.htm/Research Work-JGO, Spain, 2005.

[8] J. Guzmán, G. González, J.LL. de la Rosa, and Castán J.A., "Modelling the Human Values Scale in Recommender Systems: A First Approach", Frontiers in Artificial Intelligence and Applications Series Book, Volume: 131, IOS Press, ISBN 1-58603-6, Amsterdam, The Netherlands, 2005.

[9] E.C. Ravlin and B.M. Meglino, "Effect of values on perception and decision making: A study of alternative work values Measure", Journal of Applied Psychology, 1987.

[10] S.H. Schwartz, "A theory of cultural values and some implications for work", Applied Psychology: An International Review, 1999.

[11] S.H. Schwartz, "A Proposal for Measuring Value Orientations across Nations", The Hebrew University of Jerusalem, Jerusalem, 2003. 